\title{
AS QUATRO DIMENSÕES DO CONHECIMENTO: cognitivista, conexionista, autopoético e integral - Avançando na compreensão sobre a aprendizagem
}

\author{
Andreia de Bem MACHADO ${ }^{1}$ \\ Francisco Antonio FIALHO ${ }^{2}$
}

\begin{abstract}
${ }^{1}$ Doutoranda no Programa de Pós-Graduação em Engenharia e Gestão do Conhecimento (PPEGC) na Universidade Federal de Santa Catarina (UFSC). Mestre em Educação Científica e Tecnológica (PPGECT) na Universidade Federal de Santa Catarina (UFSC). Especialista em Alfabetização na Universidade do Estado de Santa Catarina (UDESC). Graduada em Pedagogia na Faculdade de Educação (FAED) na Universidade do Estado de Santa Catarina (UDESC) Experiência na área de Educação há mais de 20 anos e com ênfase em Educação a Distância (EaD) desde de 2004, atuando principalmente nos temas: material didático , orientação de trabalho de pós graduação a distância, planejamento, desenvolvimento, coordenação nos cursos a distância. As diferentes atividades desenvolvidas centram-se principalmente como Designer Instrucional (DI) e áreas pedagógicas relacionadas a EAD. Atualmente desenvolve trabalhos e pesquisas na área de Projeto, Metodologia e Design Instrucional para o planejamento, prática, acompanhamento e avaliação em EaD, educação corporativa, inovação, parques tecnológicos bem como na área de Mídia e Conhecimento. andreiadebem@gmail.com
\end{abstract}

${ }^{2}$ Possui graduação em Engenharia Eletrônica pela Pontifícia Universidade Católica do Rio de Janeiro (1973) e em Psicologia pela Universidade Federal de Santa Catarina (1999), mestrado em Engenharia de Produção, Ergonomia, pela Universidade Federal de Santa Catarina (1992) e doutorado em Engenharia de Produção, Engenharia do Conhecimento, pela Universidade Federal de Santa Catarina (1994). Atualmente é Professor Titular da Universidade Federal de Santa Catarina. Tem experiência na área de Engenharia e Gestão do Conhecimento, atuando principalmente nos seguintes temas: engenharia do conhecimento, mídias do conhecimento, eco-ergonomia, gestão do conhecimento e ergonomia cognitiva.fapfialho@gmail.com

Recebido em: 15/03/2015 - Aprovado em: 22/08/2016 - Disponibilizado em: 18/12/2016

\begin{abstract}
RESUMO
A questão do conhecimento permeia nossa sociedade desde os tempos dos filósofos gregos. Segundo alguns o conhecimeto é o que permite que o homem equacione os problemas do seu cotidiano. O objetivo deste artigo é conceituar o conhecimento referente ao aprendizado individual do ser humano inicialmente: na episteme dos cognitivistas; dentro da ótica dos conexionistas e na abordagem autopoiética. A título de uma epifania discute-se o conhecimento numa visão integral que enxerga os três conceitos como aspectos de uma mesma realidade. Para tanto, a metodologia utilizada foi uma pesquisa descritiva exploratória, numa abordagem qualitativa, o que permitiu, ao final, inferir algumas considerações sobre a questão do conhecimento em uma visão mais ampla e integral.
\end{abstract}

Palavras Chave: Conhecimento, Conceito de conhecimento, Dimensões do Conhecimento.

\section{THE FOUR DIMENSIONS OF KNOWLEDGE: cognitive, connectionist, autopoietic and}

\section{integral - Advancing the understanding learning}

\begin{abstract}
The question of knowledge permeates our society since the days of the Greek Philosophers. According to some "knowledge" is what allows men to solve their everyday problems. This article goal is to conceptualize knowledge regarding the individual learning of the human being: in the eyes of the cognitivists; following the optics of connectionism; and in accordance with the autopoietic approach. By way of an epiphany we discuss the knowledge in an integrated vision that understands each of the three concepts as aspects of the same reality. Therefore, the methodology used was a descriptive exploratory research, a qualitative approach, which allowed, in the end, infers some considerations on the question of knowledge in a broader and more comprehensive approach.
\end{abstract}

Keywords: Knowledge, Knowledge Concepts, Knowledge Dimensions. 


\section{Introdução}

As Ciências da Cognição estão conectadas ao trabalho do matemático, lógico e cientista da computação Alan Turing e seus experimentos relacionados à inteligência, A ideia desse cientista era criar uma máquina que simulasse a mente de um bebê, ou seja, do ser humano quando nasce e submetê-la a um processo educativo. A máquina universal de Turing, criada no ano de 1936, inspirou John von Neumann e outros. Sujeitado a perseguições culturais devido a sua opção sexual, Turing suicidou-se em 1952, antes de completar sua pesquisa sobre o conhecimento humano.

Duas correntes surgem nesta época. Uma que defende uma arquitetura simbólica, visão cognitivista clássica e outra conexionista. A arquitetura simbólica, cognitivista, companha o desenvolvimento dos primeiros computadores. Ada Lovelace, filha de Lorde Byron, já previa no século XIX que a máquina de Babbage, tetravó dos computadores atuais, poderia operar não apenas com números, mas também com qualquer tipo de símbolos. $\mathrm{O}$ conhecimento seria representado por símbolos dentro da mente humana e aprender seria construir (empiristas) ou despertar (idealistas) símbolos $^{1}$. Essa visão cognitivista do conhecimento vai servir de inspiração para a

\footnotetext{
${ }^{1}$ Em Platão o conhecimento é inato (aprender é lembrar). Para Aristóteles o conhecimento é adquirido.
}

produção da máquina digital de Neumann e os Sistemas Especialistas.

Em “A nova ciência da mente: Uma história da Revolução Cognitiva", Howard Gardner conta a história das ciências da cognição. No Simpósio Hixon datado de 1948, em que palestraram John von Neumann, Warren McCulloch e o biólogo Karl Lashley, discutia-se a forma pela qual o Sistema Nervoso controlaria o comportamento.

A Fundação Macy Jr. É sempre citada quando se fala de uma história das Ciências da Cognição. Foram dez encontros realizados em dois dias cada, no período de 1946 a 1953.

A questão central eram as causas e respostas dos mecanismos associados ao sistema biológico e social: “Circular Causal and Feedback Mechanisms in Biological and Social Systems”. A presença de cientistas de diferentes áreas do conhecimento fez com que houvesse uma dificuldade inicial nos trabalhos, principalmente com relação à comunicação entre os membros participantes, cada um falando na linguagem de suas disciplinas. Para que o diálogo pudesse ocorrer foi necessário aprender essas novas linguagens, o que demandou tempo e convívio entre os participantes.

Nesses encontros reuniam-se pesquisadores como Gregory Bateson, Margareth Mead, Warren McCulloch, Norbert Wiener, John Von Neumann, Walter Pitts, Kurt Lewin, Heinz Von Foster e Warren 
McCulloch. Esses estudos levaram a conceitos que fundaram toda a ciência moderna. Um dos campos inaugurados é o que hoje conhecemos por cibernética.

Como o cérebro trabalha a partir do erro empregando as informações daí obtidas para, posteriormente, chegar ao acerto? Os pais da cibernética foram John Von Neumann, Nobert Wiener e Warren McCulloch.

(...) Diferente da visão behavioristas de que os cérebros funcionavam em razão de estímulos externos, estes pesquisadores proponham que o cérebro seria como uma rede conexionista formada por conexões entre células, um sistema fechado em si mesmo. (FIALHO, 2011, p.16)

Relacionados aos estudos de McCulloch, estão os realizados por Humberto Maturana e Francisco Varella inicialmente durante a década de 1970 para explicar a diferença entre seres vivos e máquinas (De Máquinas e Seres Vivos). Ambos produziram a teoria da autopoiese. "Todo fazer leva a um conhecer e todo conhecer é um criar. Não conhecemos o mundo, mas 0 criamos ao intentar conhecê-lo e nos (re) criamos no processo"2.

A teoria da autopoiese explica o conhecimento como emergindo das redes de conexões que se ligam e se completam, ou seja, um sistema de conexões complexas que se unem e se relacionam mutualmente. O conhecimento é

2 MATURANA, Humberto. A árvores do conhecimento: as bases biológicas da compreensão humana. São Paulo: Palas Athena, 2001. compartilhado através dessa rede de relações e é validado por essa mesma rede.

Como se percebe, a ciência cognitivista é interdisciplinar, utilizando-se de diferentes lentes, ou seja, dos diferentes olhares das disciplinas para a compreensão da mesma. Sendo assim, esse artigo terá como objetivo conceituar o conhecimento referente ao aprendizado individual do ser humano na visão dos cognitivistas; sobre a ótica dos conexionistas; e dentro da abordagem autopoiética. A título de uma epifania discute-se o conhecimento numa visão integral que enxerga os três conceitos como aspectos de uma mesma realidade.

\section{Conhecimento Na Visão Dos Cognitivistas}

Herbert Alexander Simon foi um dos primeiros a estudar a questão da resolução de problemas através do pensamento criativo. Para esse autor o processo de pesquisa científica está atrelado a situações de descoberta.

Simon estudou a questão da invenção relacionada aos processos cognitivos atrelados ao ato de pensar do ser humano conduzindo esse a resolução de problemas imbuídos no seu contexto histórico, cultural e social.

É possível representar essa situação, segundo esse autor, através do computador, pois esse é o único que conseguiria simular os procedimentos da psique humana: "de imitar os processos do pensamento humano tais quais são produzidos realmente no cérebro 
humano diante da resolução dos problemas (e de outras atividades cognitivas e de qualquer tipo)" (SIMON, 1977.p. 265).

\section{Redes?}

\section{Ações?}

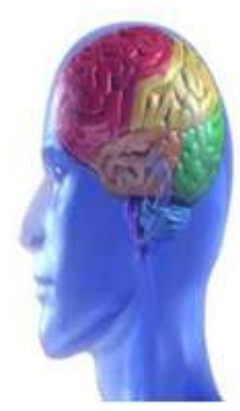

\section{Símbolos?}

Figura 1. O mistério do conhecimento

Fonte: Elaborado pelos autores (2015)

Para conceber novas formas pelas quais o ser humano possa adquirir conhecimento é necessário compreender como esse processo acontece dentro de nossos cérebros. Simon explica: "somente uma compreensão aprofundada da maneira pela qual o espírito humano trabalha pode nos ajudar a encontrar alguns meios para melhorá-las" (1984.p. 116).

Para esse autor descobrir é algo raro. Não há diferenças entre a resolução de problemas do cotidiano do nosso dia a dia ou problemas de ordem cientifica em um cenário de pesquisa. A inovação não tem segredos, ela ocorre através de elementos simples vivenciados na nossa realidade "o segredo da inovação é que não há segredo. Ela se consuma fazendo jogar combinações complexas de elementos simples" (SIMON, 1960: 69).

Simon (1984) propõe que tudo pode ser explanado pelas estruturas de conhecimento e por uma amnésia seletiva que estão na base do procedimento para resolver problemas. Essas estão atreladas as questões referentes a nossa memoria de curto e de longo prazo.
$\mathrm{O}$ primeiro mecanismo (memória de curto termo) trabalha sem tirar os olhos para não perder o rumo, e o segundo (memória de longo termo) rejeita o acabado. O segundo armazena suas rejeições na desordem. O pesquisador é guiado por um mapa das caminhadas precariamente mantidas na memória imediata. Quando ele se encontra diante de um impasse, ele pode abandonar esta via e esquecer o mapa das caminhadas inicialmente adotadas. No momento em que explora outra via, ele guarda em sua memória permanente as informações armazenadas quando da primeira tentativa como o saber rudimentar do mapa da caminhada inicial; novas estruturas simbólicas podem então reorganizar de outra maneira esses elementos e dar lugar a novos mapas de caminhada. (MACHADO, 2010,p. 2)

Outro ponto na concepção de Simon é acerca da descoberta que o conhecimento adquirido pela descoberta ocorre através de processos psicológicos e que são iguais para o primeiro e para o que reinventa a questão

Eis porque, o programa
Bacon, utilizando os
mesmos dados que aqueles
que dispunham os
primeiros inventores
(Kepler e Ohm) chegam às
mesmas leis, ele
(re)descobre.
demonstracon que a
organização dos processos
necessários para fazer
descobertas científicas é
essencialmente a mesma
daquela requerida pela


maioria dos sistemas de resolução de problema (SIMON, 1984,p. 14).

O conhecimento é realizado através descobertas de processos teóricos da ciência da cognição que permite ao ser humano descobrir através da percepção, ou da cognição uma maneira de explicar o mundo da melhor forma possível, ou seja, a representação do mundo que o cerca da forma mais precisa possível.

Nessa abordagem o conhecimento é conceituado como agrupamento de representações de mundo, formado por uma série de circunstâncias que comporem nosso cotidiano. Sendo assim o conhecimento é resultante de nossas vivências sensórias, de uma explicitação/representação da realidade que nos cerca.

As primeiras calculadoras operavam sobre números. Ada Lovelace em uma epifania pitagórica já previa que seria possível operar sobre qualquer tipo de símbolos. Computadores poderiam escrever poesia ou compor músicas (como já o fazem), mas jamais seriam capazes de exibir inteligência.

O argumento de Lady Lovelace foi refutado por Turing. Será que máquinas de arquitetura simbólica serão capazes de se tornar inteligentes? Para os que defendem uma arquitetura conexionista, a resposta é não.

A máquina simbólica tem entradas e saídas. Símbolos são processados e novos símbolos são criados.
Para emular qualquer cérebro basta colocar na memória os símbolos existentes e copiar os programas que este usa para processar símbolos externos e construir novos símbolos.

Se essa ideia fosse verdadeira já teríamos hoje máquinas inteligentes.

\section{Conhecimento Na Visão Dos Conexionistas}

John McCarthy e Marvin Minsky organizaram no Darthmouth College, em 1956, uma conferência que teria marcado o início da "Inteligência Artificial", como ciência. $\mathrm{Na}$ época dos "Sistemas Especialistas" acreditava-se que as máquinas simbólicas poderiam se tornar inteligentes. John von Neumann, o criador da arquitetura dos computadores atuais, percebeu antes de sua morte, em 1976, que a arquitetura do cérebro humano é diferente da dos computadores de então: “A lógica terá de passar por uma metamorfose e virar neurologia",

Os defensores da visão conexionista insistem que não basta operar sobre símbolos para construir novos símbolos, mas que é preciso imitar a arquitetura do cérebro humano. O cérebro é, sem dúvida, digital, mas não apenas digital. Somos máquinas analógicas capazes de operar sobre o mistério e, dele, extrair heurísticas e algoritmos.

\footnotetext{
${ }^{3}$ The Computer and the Brain. New Haven: Yale University Press, 1958 p.80
} 
Douglas Hofstadter (1979) em seu livro "Godel, Escher and Bach" afirma que para se chegar à Inteligência Artificial é preciso compreender como se dá a imaginação humana.

Walter Isaacson (2014) ${ }^{4}$ explica o conceito de forma humorada: "Faça ao Google uma pergunta objetiva como: "Qual é a profundidade do mar Vermelho?", e ele no mesmo instante responderá "2211" metros, coisa que nem seus amigos mais inteligentes sabem. Faça-lhe uma pergunta fácil como “jacaré sabe jogar basquete?”, e o Google não terá a menor ideia, muito embora uma criancinha de dois anos seja capaz de responder, depois de rir um bocado".

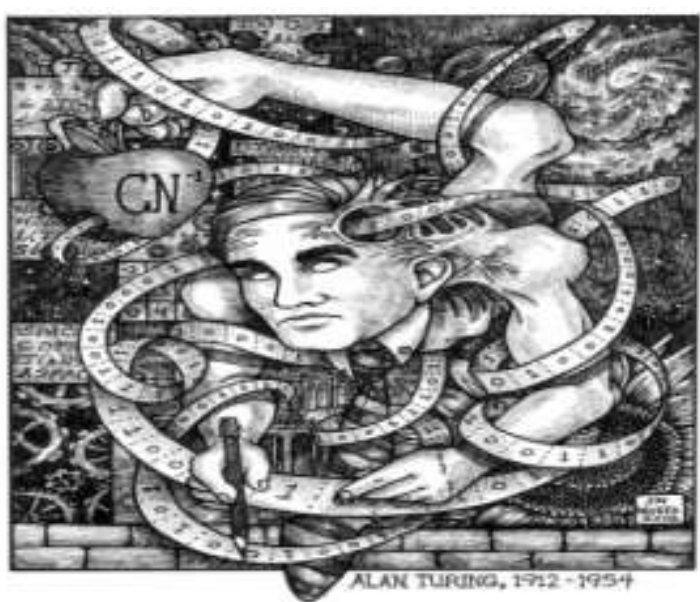

Figura 2. A máquina universal de Turing Fonte:https://edsonjnovaes.wordpress.com/2014/07/02 /o-teste-de-turing/

Como criar máquinas com senso de humor e capazes de exibir emoções? O cérebro humano não é somente digital e analógico, mas funciona de forma distribuída como uma rede dentro de redes.
A máquina conexionista funciona como um computador paralelo formado por bilhões de neurônios (por enquanto as máquinas estão na granularidade dos milhões).

A rede aprende com o seu operar, ajustando as suas sinapses até encontrar respostas adequadas.

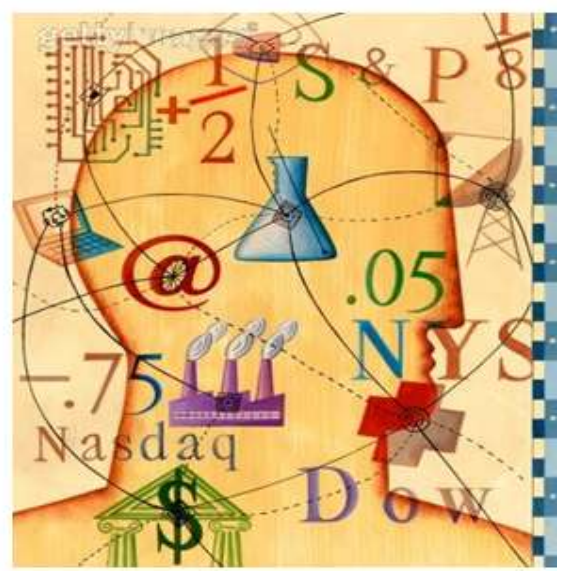

Figura 3. A máquina conexionista

Fonte:https://paideiablog.wordpress.com/2010/03/09/

A riqueza cognitiva se dá nas interações. Somos redes dentro de redes, em processo de aprendizagem.

\section{Conhecimento na Visão Autopoiética}

Maturana e Varela estabeleceram a teoria da autopoiesis, que se sustenta na ideia de que seres vivos se autofabricam. Enquanto as máquinas alopoiéticas produzem "para fora, para o mundo", as máquinas autopoiéticas produzem a si mesmos. Estes cientistas se propõem a entender a natureza autônoma da organização biológica e entender como a identidade pode ser

\footnotetext{
${ }^{4}$ Os Inovadores. Companhia das Letras, 2014
} 
mantida durante a evolução que gera a diversidade ${ }^{5}$.

No livro "Árvore do Conhecimento" Varela (1989, p. 219)resumeas duas teses fundamentais que tiveram grande impacto depois de 1946.

\begin{tabular}{|c|c|c|}
\hline & $\begin{array}{c}\text { Sistemas } \\
\text { heterônomos }\end{array}$ & $\begin{array}{c}\text { Sistemas } \\
\text { autônomos }\end{array}$ \\
\hline $\begin{array}{c}\text { Lógica } \\
\text { fundamental de } \\
\text { operação }\end{array}$ & correspondência & coerência \\
\hline $\begin{array}{c}\text { Tipo de } \\
\text { organização }\end{array}$ & $\begin{array}{c}\text { entrada/ saída } \\
\text { funções de } \\
\text { transferência }\end{array}$ & $\begin{array}{c}\text { fechamento } \\
\text { operacional } \\
\text { comportamentos } \\
\text { próprios }\end{array}$ \\
\hline $\begin{array}{c}\text { Modo de } \\
\text { interação }\end{array}$ & $\begin{array}{c}\text { um mundo dado } \\
\text { com instruções e } \\
\text { representações }\end{array}$ & $\begin{array}{c}\text { um mundo } \\
\text { emergente de } \\
\text { significados }\end{array}$ \\
\hline Base teórica & John Von Neumann & Norbert Wiener \\
\hline
\end{tabular}

Tabela 1. As visões autônoma e heterônoma sob vários domínios

Fonte: A Árvore do Conhecimento

Maturana nos traz duas contribuições importantes. Em primeiro lugar, rejeita a concepção de inteligência como atributo individual independente.Inteligência não é uma capacidade individual, mas relacional.

Sendo assim nossa ação revelará nas relações sociais o nosso comportamento, intitulado por Varella comportamento inteligente que segundo ele é contextual, manifesta-se no contexto. Já a segunda teseexplicita que o comportamento Varela (1989, p. 219)

(..) inteligente manifesta-se na relação com o outro "domínio consensual" - e com o meio ambiente "adaptação ontogênica”.Realiza-se, portanto, através da

\footnotetext{
${ }^{5} \mathrm{O}$ trabalho de Humberto Maturana e Francisco Varela por Edla Faust Ramos
}

flexibilidade
consensualidade:

da

Manguel citado por Paulo Freire ${ }^{7}$ já dizia que somos letras nas páginas de um grande livro e que, ao nos modificarmos, modificamos esse livro. Maturana fala do caminhante sobre a praia. Ao fim do caminho nem a praia e nem o caminhante são mais os mesmos.

$\mathrm{Na}$ teoria da autopoiesis o importante não é a representação, mas a ação. Piaget já dizia que sua teoria era uma gestaltkreis. Não apenas um "todo", mas um "todo" sobre o qual se opera para obter um resultado. Conhecer é criar. Conhecer é um processo e não uma "coisa".

O universo é uma rede hipertextual de significados quântica e complexa. Somos uma rede dentro desta rede, constantemente nos modificando e, por conseguinte, modificando as redes: "os todos" dos quais somos parte.

Conhecer não é individual, mas coletivo. Estamos em contínua interação com os outros fora de nós e os outros dentro de nós.

A máquina autopoiética não tem entradas e nem saídas. Funciona por meio de perturbações internas.

${ }^{6}$ CUNHA FILHO, José Leão: A certeza da incerteza educa. http://www.humanitates.ucb.br/3/certeza.htm ${ }^{7}$ FREIRE, P. A importância do ato de ler em três artigos que se completam. São Paulo: Cortez, 2005. 


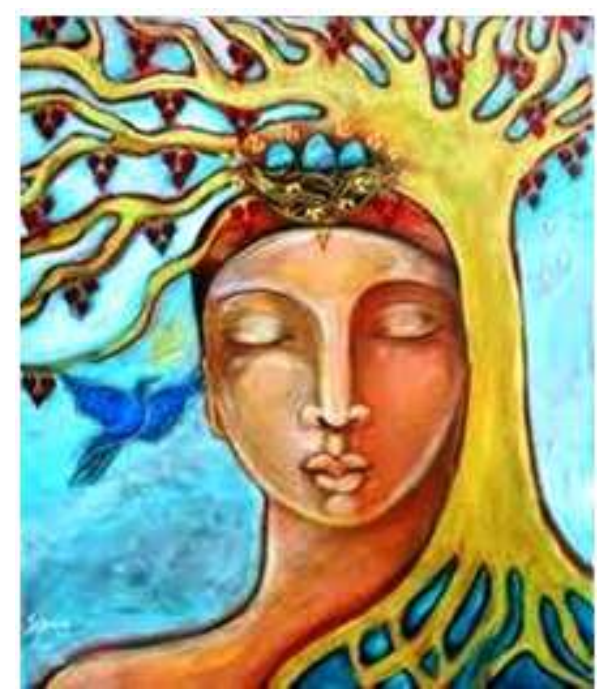

Figura 4. A máquina autopoiética

Fonte:http://cristianegantus.blogspot.com.br/2012/10/a utopoiese-cultura-e-sociedade-por.html

Para Maturana, o termo "autopoiese" significa o "centro da dinâmica constitutiva dos seres vivos". Seres vivos são ao mesmo tempo autônomos e dependentes. Trata-se, pois, de um paradoxo.

Nossas fomes internas nos forçam a nos abrir para o mundo de forma intencional, em busca de algo que sacie estas fomes. Trata-se de uma máquina "ativa" e não "reativa".

\section{Conhecimento Numa Visão Integral}

Baruch Spinosa sustentava já no século XVI que a ação de Deus é uma manifestação necessária de sua essência. Ele é um ser que se causa a si mesmo, que se autoproduz. Aqui está, seguramente, o que três séculos depois viria a ser chamado de autoprodução, diz Humberto Mariote.

Piaget diz que a criança explica o homem. O primeiro tipo de raciocínio, uma espécie de proto-raciocínio, é a descoberta por acidente, que se dá, praticamente, desde o início da vida do bebê. A forma pela qual o conhecimento se manifesta é melhor explicável pela teoria da autopoiesis. Os esquemas sensórios motores do tipo <contexto: operador: resultado> mostram que a assimilação é, antes de tudo, ação no mundo. A criança ao nascer se comporta como uma máquina autopoiética.

Por volta dos dois anos de idade, para a criança, existem dois planos de realidade: o do brinquedo, no qual os dados do mundo são assimilados ao eu da criança, com predomínio da fantasia, e o da observação, quando ocorre acomodação, isto é, o eu da criança se submete aos dados do mundo externo. As redes neurais começam seu processo de aprendizagem Sinapses se estabelecem e a criança aprende por imitação, comportando-se como uma máquina conexionista.

Immanuel Kant, no século XVIII, em seu livro Crítica da faculdade do juízo, se refere ao organismo como um todo que se autoproduz. Plotino, expoente da filosofia neoplatônica já havia falado em auto causalidade no sentido de autoprodução. Darcy Ribeiro já dizia que o ser humano vai se construindo na linguagem.

Se ao nascer nos autoproduzimos pela ação, a partir da linguagem, nos transformamos em símbolos a interagir com outros símbolos em busca de significados. A máquina simbólica se estabelece. A cultura vai, pouco a pouco estabelecendo a máquina 
simbólica como dominante. A lógica passa a predominar sobre a emoção. Aprender se torna "sem graça".

Entre os sete e onze anos o egocentrismo intelectual vai gradativamente cedendo espaço ao pensamento lógico. Os esquemas simbólicos se tornam, agora, esquemas conceituais concretos, verdadeiros esquemas mentais em que a realidade passa a ser estruturada pela razão e não mais pela assimilação egocêntrica. Nos assemelhamos, cada vez mais, às máquinas de arquitetura simbólica.

A criança aprende a representar o mundo por meio de sinais e símbolos, ou seja, imagens e palavras. Reorganiza constantemente seu retrato do mundo através de brinquedos imaginários, conversação, indagação, audição e experimentação. Começa, então, a interiorização dos esquemas de ação, sob a forma de representações. Aos cinco anos, mais ou menos, as organizações representativas são estabelecidas, seja na forma de configurações estáticas, seja sob uma assimilação à própria ação.

Com as estruturas operatórias formais, que começam a se constituir por volta dos onze, doze anos, chegamos à fase do processo de desenvolvimento em que as operações se libertam do contexto psicológico das ações do sujeito. O conhecimento ultrapassa o real para inserir-se no possível e para relacionar diretamente o possível ao necessário, sem a mediação indispensável do concreto.
Trabalha-se sobre hipóteses e não mais sobre objetos.

A criança estudada por Piaget não é a mesma de hoje. A criança desse novo milênio navega pelas redes, aprende a construir conhecimento pela interação não só com humanos, mas também com artefatos.

Antes o fim da educação era a transformação do humano em máquina. Aprendíamos a operar sobre símbolos. A inteligência linguística e a lógico-matemática eram privilegiadas. Ao fim do processo educativo éramos convidados a trocar nossa humanidade pela lógica fria dos cálculos e previsões.

Em contraponto com esta realidade do passado, a tecnologia vem virtualizando o mundo. As interações, no passado, eram poucas e limitadas a um único horizonte cultural. As redes neurais internas se reproduzem, agora, no ciberespaço. Somos neurônios de um enorme cérebro coletivo. $\mathrm{O}$ tempo todo estamos estendendo sinapses para mundos novos e encantadores.

Falamos em comunidade de prática, lugares em que ocorre uma "aprendizagem situada", que enfatiza um entendimento social e histórico-cultural que compreende a pessoa em sua totalidade, na sua relação com a comunidade em que se situa, e não como um ser que se sujeita ao papel de receptor de um corpo de conhecimento sobre fatos relacionados ao mundo (SENSE; BADHAM, 2008). 
Jane Lave (1991) afirma que qualquer forma de conhecimento se situa no poder para renegociar o significado do passado e do futuro, para construir o significado das circunstâncias do presente. Reforça-se também a necessidade de localizar onde ocorre a aprendizagem, contextualizando-a e situando-a, apresentando suas peculiaridades sociais, históricas, culturais, econômicas e políticas, de modo que as circunstâncias analisadas sejam delimitadas com o objetivo de não descolar o processo de aprendizagem do lócus em que ocorre. Afinal, “o significado não existe dentro de nós nem no mundo exterior, mas na relação dinâmica da vivência no mundo" (WENGER, 1998, p. 54).

Por meio de metáforas e metonímias observamos a reação das máquinas conexionistas e autopoiéticas em (oper)ação dentro destas redes. A linguagem do ego, simbólica e lógica, das verdades incontestes, perde espaço para a linguagem da alma cheia das incertezas de que fala Edgar Morin. A primeira quer se impor pela retórica, a segunda só deseja compartilhar lembranças.

A abdução inventa ou propõe uma hipótese. A dedução explica as hipóteses, deduzindo a partir delas as consequências necessárias que possam ser testadas. A indução consiste no processo de teste das hipóteses (FANN, 1970, p. 10; GHIZZI, 2006). A abdução apresenta semelhanças com a compreensão que temos de intuição. (SANTAELLA, 2004, p. 47). Nós só entendemos o que estamos preparados para interpretar. (PEIRCE, 1998, 2010)

Ari Raynsford, doutor em engenharia nuclear pelo Massachusetts Instituteof Technology (MIT), baseado na teoria integral de Ken Wilber, pretende compreender de maneira completa a evolução e as ações do homem na Terra. Em "Cinco mentes para o Futuro" Howard Gardner compara Wilber a Peirce (da Semiótica), que seriam "polímatas" (uma equipe interdisciplinar contida em um único homem).

Chamemos de máquina humana essa que se manifesta, ao mesmo tempo, como simbólica, conexionista e autopoiética, que atuam não em oposição, mas de forma complementar. É do funcionamento conjunto destas máquinas que se pretende construir o homem do novo milênio.

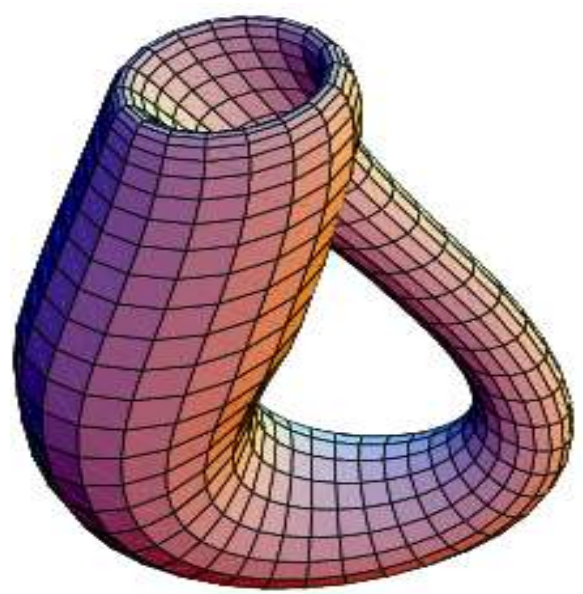

Figura 5. A Máquina humana Fonte: Os autores

A figura 5 mostra uma garrafa de Klein, que é obtida pela colagem de duas fitas de Mobius. Não possui bordas, esquerda ou 
direita, dentro e fora. Trata-se de um contínuo que se abre para o infinito.

\section{Conclusões}

Teilhard de Chardin ${ }^{8}$ acreditava que a inteligência seria uma emergência, consequência da complexidade das relações que uma entidade estabelece com o universo a sua volta.

Segundo Roger Martin, estamos imersos em mistério. Usamos nossos diferentes tipos de raciocínio para extrair desse mistério, heurísticas. Heurísticas são regras que usualmente funcionam, mas não em todas as circunstâncias. Algoritmos são prescrições para resolver um dado problema.

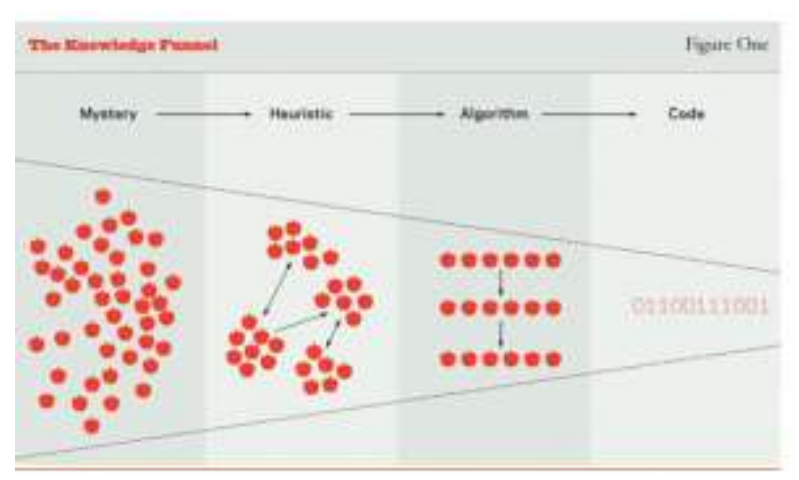

Figura 6: $\mathrm{O}$ funil do conhecimento.

Fonte: Adaptado de MARTIN (2009)

A máquina simbólica é incapaz de operar sobre os mistérios, o máximo que consegue é estabelecer heurísticas e empregar algoritmos. A máquina conexionista ajusta neurônios e sinapses para se adaptar ao mundo. A máquina autopoiética é um sistema

${ }^{8}$ TEILHARD DE CHARDIN, P. 1959. L'Avenir de L'Homme. Paris, Seuil, 406 p. TEILHARD DE CHARDIN, P. 1971. El fenomeno humano. Barcelona, Taurus, $383 \mathrm{p}$. fechado que só se abre por perturbações internas.

A educação do passado depositava algoritmos nas mentes dos alunos, verdades transmitidas de geração para geração. Erros que o cozimento do tempo nos faz crer que sejam verdades, dizia Gilles Deleuze.

A educação do futuro trabalha com as incertezas, aprende sobre o mistério e nos ensina a amá-lo e não mais temê-lo. Transforma cada aluno em uma metamorfose ambulante que cria mundos e se recria no processo.

É óbvio que se torna urgente uma nova pedagogia, que explore todas as possibilidades das máquinas, simbólicas, conexionistas e autopoiéticas que somos. Essa nova pedagogia, porém não pode esquecer que somos muito mais do que isso. Somos mistério em busca de significado.

\section{Referências}

BRINK, J. R. fe HADEN, C. R., Eds. The Computer and the Brain: An International Symposium in Commemoration of John von Neumann of Annals of the History of Computing (special number). 1989.

FANN, K. T. Peirce's theory of abduction .The Hague: Martinus Nijhoff, 1970.

FIALHO, F. A. P. Psicologia das Atividades Mentais. 1. ${ }^{\text {a }}$ ed. Florianópolis: Editora Insular, 2011.

FREIRE, P. A importância do ato de ler em três artigos que se completam. São Paulo: Cortez, 2005.

\section{GHIZZI, E. B. Arquitetura em diagramas:}


uma análise da presença do raciocínio dedutivo-diagramático no processo projetivo em arquitetura. CognitioEstudos, São Paulo, v. 3, n. 2, p. 109-124, jul.- dez. 2006. Disponível em:

http://www4.pucsp.br/pos/filosofia/Pragmatis mo/cognitio_estudos/cognitio_estudos.htm Acesso em: 21 ago. 2010.

ISAACSON, Walter. Os inovadores : Uma biografia da revolução digital / Walter Isaacson. Tradução de Berilo Vargas, Luciano Vieira Machado e Pedro Maria Soares - 1a ed. - São Paulo : Companhia das Letras, 2014.

LAVE, Jean. WENGER,

Etienne (1991). Situated Learning:

Legitimate Peripheral Participation.

Cambridge: Cambridge University

Press. ISBN 0-521-42374-0.; first published in 1990 as Institute for Research on Learning report 90-0013

MACHADO, C.J.S. O modelo explicativo de Herbert Alexander Simon sobre a descoberta científica- Revista de Ciência da Informação, 10(1), 2010. Disponível em:http://dgz.org.br/fev10/Art_03.htm acesso em 30 de abril de 2015.

MATURANA, Humberto. A árvore do conhecimento: as bases biológicas da compreensão humana. São Paulo: Palas Athena, 2001.

BARREIRA, Luis História e Historiografia : como Escritas Recentes da História da Educação Brasileira (19711988). 1995. 220pp. Tese

(DoutoradoemHistória da Educação) UNICAMP, Campinas.

MARTIN, The design of business: why design thinking is the next competitive advantage. 2009.

PEIRCE, C. S. The collected papers of
Charles Sanders Peirce.Ed. de C. Hartshorne; P. Weiss \& A. W. Burks. Cambridge, Harvard University Press, 19311958. 8 v. (CP).

The essential Peirce: selected philosophical works. Ed. de N. Houser et al. Bloomington, Indiana University Press, 1992. 2 v. . Semiótica. Trad. de J. T. Coelho Neto. São Paulo, Perspectiva, 2000. (Coleção Estudos, 46).

RAMOS, Edla Maria Faust Ramos. Análise ergonômica do sistema hiperNet buscando o aprendizado da cooperação e da autonomia. (1992-1996). 1996. 295 p. Tese(Doutorado em Engenharia de Produção) - UFSC, Florianópolis.

SANTAELLA, L. O método anticartesiano de C. S. Peirce. São Paulo: Editora UNESP, 2004.

SENSE, A. J., BADHAM, R.. Cultivating situated learning within project management practice: A case study exploration of the dynamics of projectbased learning. International Journal of Managing Projects in Business, 2008 1(3), 432-438.

SIMON, H. Models of discovery, Dordrecht: D.Meidel Publishing Compagny. 1977.

H. A., L'Unitédesarts et desSciences : lapsychologie de lapensée et de ladécouverte, AFCET INTERFACES, $\mathrm{n}^{\circ}$ 15: 1 -16.

1984.

H.A..The New Science of Management Decision. New York, NY: Harper and Row. 1960.

H.; WEBER, R.J. and PERKINS, D.N..How to invent artifacts and Ideas. New Ideas in psychology, 7(1): 49-72. 1989.

TEILHARD de Chardin, P. L'Avenir De L’Homme. Paris, Seuil, 1959. 406 p. 
TEILHARD de Chardin, P. 1971. El

fenomeno humano. Barcelona, Taurus, 383

p.

WENGER, E. Communities of practice:

learning, meaning, and identity. New York:

Cambridge University Press, 1998. 